\title{
Fluoride Levels of Human Plasma and Breast Milk
}

\author{
Yaḡmur Senera, DDS, PhD \\ Gül Tosuna, DDS, PhD \\ Firdevs Kahvecioḡlub, DDS, PhD \\ Alparslan Gökalpc, DDS, PhD \\ Hasan Koç, MD
}

\section{ABSTRACT}

Objectives: The aim of this study was to determine the fluoride levels in breast milk and plasma of lactating mothers who regularly consumed drinking water with low levels of fluoride.

Methods: One hundred twenty five healthy mothers aged between 20-30 years old who had given birth within 5-7 days were included in the study. Besides being otherwise healthy, the primary selection criteria stipulated the absence of fluoride supplement consumption one month before delivery. Approximately $5 \mathrm{ml}$ breast milk and $5 \mathrm{ml}$ blood samples were obtained from each participating mother at a hospital setting, where the mothers were scheduled for a regular hospital diet. The blood samples were centrifuged in fluoride-free heparinized polyethylene tubes and stored at $-18^{\circ} \mathrm{C}$ until measurements were made. Breast milk samples were directly refrigerated as with blood samples until measurements. The fluoride concentrations of milk and blood samples were assessed using an ion-selective fluoride electrode combined with an ion analyzer.

Results: The fluoride levels of the plasma and breast milk samples were measured as $0.017 \pm 0.011$ $\mathrm{ppm}$ and $0.006 \pm 0.002 \mathrm{ppm}$, respectively. The fluoride concentration of plasma was significantly higher than that of breast milk $(P<.01)$. Correlation analysis revealed a significant relation between the groups $(\mathrm{P}<.01)$.

Conclusion: A limited level of fluoride transmission from plasma to breast milk was detected. Nevertheless, a significant correlation between the fluoride concentrations of breast milk and plasma was evident. (Eur J Dent 2007;1:21-24)

Key words: Breast milk; Fluoride; Plasma.

\section{INTRODUCTION}

Since various forms of fluorides have met wide acceptance for use in the prevention of dental caries, the metabolism of fluoride is of considerable interest. ${ }^{1-3}$ The human organism is exposed to

$\square$ a Assistant Professor, Selçuk University,

Faculty of Dentistry, Department of Pedodontics.

b Research Fellow, Selçuk University,

Faculty of Dentistry, Department of Pedodontics.

Professor, Selçuk University,

Faculty of Dentistry, Department of Pedodontics.

d Professor, Selçuk University,

Faculty of Medicine, Department of Paediatrics.

$\square$ Corresponding author: Dr. Yaḡmur SENER

Selcuk Universitesi, Dis Hekimligi Fakultesi,

Pedodonti Anabilim Dalı

42079 Kampus, Konya-TURKEY

Tel:+90 3322231158

Fax:+903322410062

e-mail: yagmur_senerahotmail.com

fluoride in a number of ways. Ingestion of fluoride is accomplished through various foods; drinking water and fluoride containing products comprising dentifrices, mouth rinses, tablets, drops, etc. ${ }^{4-6}$ Hard tissues are known to be the major sites of fluoride accumulation in the human body. Approximately $99 \%$ of the total body burden of fluoride is retained in bones and teeth, with the remainder distributed in highly-vascularized soft tissues. 4,5 Kidneys are the primary route for the removal of fluoride from the body. Other routes of fluoride excretion are sweat, feces, saliva and breast milk of lactating mothers. ${ }^{4.5,7}$,

Breast milk is the major dietary intake of infants in the early stage of life. The level of fluoride in breast milk plays an important role as a fluoride supplement to the infant. ${ }^{8}$ Conversely, the concentration of fluoride could be deemed critical regard- 
ing the potential dental fluorosis that may result from high concentrations of dietary fluoride. 9,10

Plasma is the biological fluid into which fluoride must pass for its distribution elsewhere in the body as well as its elimination from the body. For these reasons, plasma is often referred to as the central compartment of the body. ${ }^{6}$ Factors that include fluoride intake from various sources may affect plasma fluoride levels, and thus fluoride content of breast milk.

The aim of this pilot study was to determine the fluoride levels of breast milk and plasma of lactating mothers and the correlation between breast milk and plasma fluoride levels in mothers who regularly consume drinking water with low levels of fluoride.

\section{MATERIALS AND METHODS}

One hundred twenty five mothers aged between 20-30 years old with hospitalized newborns due to icterus neonatorum were included in the study. Signed consent was obtained from the participants after explanations regarding the study protocol. The human ethic committee of Selcuk University Experimental Research Center (SUDAM) approved this study (Approval No:2004-034).

Besides being otherwise healthy, the primary selection criteria stipulated the absence of fluoride supplement consumption one month before delivery. The participants regularly consumed drinking water from the same city supply which has been previously shown to contain low levels of fluoride (approx. 0.3 ppm). ${ }^{11}$ The mothers consumed a regular hospital diet.

Milk and plasma samples were collected from lactating mothers within 5 to 7 days after delivery. For milk samples, the breast was swabbed with cotton wool and distilled water before milk collection. The mother was instructed to press the breast gently to facilitate collection of $5 \mathrm{ml}$ of milk into a polyethylene tube. At the same appointment, $5 \mathrm{ml}$ of blood was obtained and transferred into a fluoride-free heparinized polyethylene tube. Thereafter, the plasma was separated from the blood by centrifugation for $3 \mathrm{~min}$ at $3500 \mathrm{~g}$. Milk and plasma samples were further stored at $-18^{\circ} \mathrm{C}$ until analyses. Before fluoride measurements, the samples were thawed at room temperature.

To determine fluoride concentrations, equal volumes of TISAB II buffer (Orion Research, U.S.A.) was added into the samples. All samples were homogenized using magnetic stirrers throughout the measurements. An ion-selective electrode (Model 96-09, Orion Research, USA) was used in conjunction with a Model EA 910 ion analyzer (Orion Research, USAl to measure the fluoride concentrations of the breast milk and plasma samples.

Paired t test was used to determine the differ- ences between fluoride concentration of breast milk and plasma. Pearson correlation analysis was used to assess any possible relationship between plasma and breast milk fluoride levels. ${ }^{12}$

\section{RESULTS}

The concentrations of fluoride in breast milk and plasma are presented in Table 1. The mean fluoride concentration of the plasma samples was $0.017 \pm 0.011 \mathrm{ppm}$ (range 0.006-0.054 ppm). The mean fluoride concentration of the breast milk samples was 0.006 $\pm 0.02 \mathrm{ppm}$ (range 0.003-0.011 ppm).

Paired t test showed that the fluoride concentrations of plasma were significantly higher than those of the breast milk $(P=.000)$. Pearson analysis revealed a significant correlation between the fluoride concentrations of breast milk and of plasma $(P=$.000). When a mother's plasma fluoride concentration was above (or below) the mean plasma fluoride level of the entire study group, the breastmilk fluoride levels were affected accordingly.

\section{DISCUSSION}

Several methods are used to determine fluoride levels in biologic tissues that include spectrophotometry, ${ }^{13}$ gas chromatography, ${ }^{14}$ capillary electrophoresis, ${ }^{15}$ micro diffusion, ${ }^{16}$ and ion analysis in conjunction with ion-selective electrodes. ${ }^{17}$ As utilized in the present study, the most common procedure used to quantify free fluoride anion is the ion-selective electrode. ${ }^{18}$

The plasma fluoride concentration displays an increase along with fluoride intake. This increase is, however, attenuated due to distribution to the interstitial and intracellular fluid uptake by calcified tissues and renal excretion. ${ }^{5}$ The literature contains a wide range (0.008-0.045 ppm) of reported normal plasma fluoride concentrations. ${ }^{6,18}$ The diversity of values may have been due to the inclusion of fasting individuals as subjects in contrast to other studies employing non-fasting participants. ${ }^{18}$ Certainly, other factors that include methodological variations as well as the fluoride levels of drinking-water consumed by subjects should have a strong impact on the reported values. ${ }^{18} \mathrm{Li}$ et al ${ }^{19}$ reported a mean plasma fluoride concentration of $0.106 \pm 0.076 \mathrm{ppm}$ in 127 subjects. In their study, the subjects were selected from a region with the drinking water fluoride concentra-

Table 1. Fluoride concentrations of breast milk and plasma.

\begin{tabular}{lccc}
\hline & Min & Max & Mean \pm SD \\
\hline Plasma $(n=125)$ & 0.006 & 0.054 & $0.017 \pm 0.011$ \\
Breast milk $(n=125)$ & 0.003 & 0.011 & $0.006 \pm 0.002$ \\
\hline
\end{tabular}


tions of $5.03 \mathrm{ppm}$. In the present study the mean plasma fluoride concentration was $0.017 \pm 0.011$ ppm. Our finding corroborates those of Fejerskow et $\mathrm{al}^{6}$ and World Health Organization (WHO). ${ }^{18}$

Breast milk possesses unique nutritional, biochemical, anti-infective and anti-allergic properties. As breast-fed infants obtain fluids almost exclusively from their mothers, breast milk represents an important way for delivering fluoride with certain levels to infants. ${ }^{20}$ The level of fluoride in human milk has been a topic of investigation for many years. Medical literature contains a wide range for fluoride levels in breast milk. It is probable that problems with the analysis of fluoride have been contributory. According to the $\mathrm{WHO},{ }^{18}$ the breast milk fluoride levels range from $<0.002$ to about $0.1 \mathrm{ppm}$, with most values being between $0.005-0.010 \mathrm{ppm}$. The mean breast milk fluoride concentrations obtained here in $(0.006 \pm 0.002 \mathrm{ppm})$ are in line with the WHO. ${ }^{18}$ Dabeka et $a l^{8}$ showed that the concentration of fluoride in breast milk was related to the content of the drinking-water consumed by the mothers. The mean concentration of fluoride in breast milk obtained from 32 women consuming drinking water that contained $<0.16$ ppm was 0.004 ppm, whereas breast milk obtained from 112 women consuming drinking water containing $1 \mathrm{ppm}$ reportedly was 0.009 ppm. ${ }^{8}$ Similar levels of fluoride concentrations of breast milk and colostrum (0.008 ppm) have been reported by Spak et al. ${ }^{1}$ However, Spak et al ${ }^{1}$ found no significant difference in breast milk fluoride concentrations of mothers living in areas with low and high drinking-water fluoride concentrations.

In the present study, the strict selection criteria which stipulated absence of recent use of fluoride supplements was a preventive measure to control variables that could interfere with the results. Additional limitations included selection of patients from a region with low drinking water fluoride levels (<0.3 ppm). In light of previous work, ${ }^{8}$ however, it is apparent that the fluoride concentration of breast milk in mothers regularly consuming higher concentrations of fluoridated water is still within normal limits.

Theoretically, a limited transfer of fluoride from plasma to breast milk should occur. ${ }^{21}$ The mechanism(s) responsible for the selective transfer of fluoride into breast tissue is obscure. ${ }^{21}$ It is thought that a physiological plasma-milk barrier functions against to fluoride. 1,2,6 Despite high doses of supplementary fluoride administered to the mother, the child receives a maximum dose of only $0.2 \%$ of the mother's fluoride intake. ${ }^{1,2}$ The results obtained in our study confirmed these conclusions. It should, however, be noted that the fluoride content transferred through breast milk is less than those present in cow's milk and in infant formulas, utilized as routine substitutes for breast milk. Rahul et $\mathrm{al}^{3}$ found that fluoride concentrations of various commercially available infant milk formulations ranged from $1.95 \mathrm{ppm}$ to $7.45 \mathrm{ppm}$ and fluoride content of cow's milk samples was $0.12 \mathrm{ppm}$; values exceeding those of breast milk.

\section{CONCLUSIONS}

It has been verified by the positive correlation between plasma and breast-milk fluoride concentrations in subjects selected meticulously in terms of low drinking water fluoride levels. While the results of the present study confirm previous data regarding the difference between plasma and breast-milk fluoride concentrations, it is evident that more research, coupled with a wider study population is indicated to clarify the exact interactions between plasma fluoride levels and those of breast milk.

\section{REFERENCES}

1. Spak CJ, Hardell LI, De Chateau P. Fluoride in human milk. Acta Paediatr Scand 1983;72:699-701.

2. Ekstrand J, Spak CJ, Falch J, Afseth J, Ulvestad H. Distribution of fluoride to human breast milk. Caries Res 1984; 18:93-95.

3. Rahul P, Hedge AM, Munshi AK. Estimation of the fluoride in human breast milk, cow's milk and infant formulate. $J$ Clin Pediatr Dent 2003;27:257-260.

4. Mellberg JR, Ripa LW, Leske GS. Fluoride in Preventive Dentistry. Chicago: Quintessence Publishing; 1983.

5. Whitford G. The Metabolism and Toxicity of Fluoride. $2^{\text {nd }}$ ed. Switzerland: Karger: 1996.

6. Fejerskov 0, Ekstrand J, Burt BA. Fluoride in Dentistry. $2^{\text {nd }}$ ed. Copenhagen: Munsksgaard,1996.

7. World Health Organization. Fluorides and oral health: Technical Report Series 846. Switzerland: 1994.

8. Dabeka RW, Karpinski K, McKenzie A, Bajdik C. Survey of lead, cadmium and fluoride in human milk and correlation of levels with environmental and food factors. Food Chem Toxicol 1986;24:913-921.

9. Fejerskow O, Manji F, Baelum V. The nature and mechanism of dental fluorosis in man. $J$ Dent Res 1990;69:699700.

10. Ekstrand J, Fomon SJ, Ziegler EZ, Nelson SE. Fluoride pharmacokinetics in infancy. Pediatr Res 1994;35:157-163.

11. Sener Y, Koyuturk AE, Gokalp A. The fluoride levels of community water supplies in Konya city. The Journal of Hacettepe Faculty of Dentistry (in Turkish) 2003;27:2-6.

12. Brunette DM. Critical Thinking: Understanding and evaluating dental research. $1^{\text {st }}$ ed. Chicago: Quintessence Publishing Co, 1996.

13. Greenhalgh R, Riley JP. The determination of fluoride in natural waters, with particular reference to sea water. Anal Chim Acta 1961;25:179-188.

14. Fresen JA, Cox FH, Witter MJ. The determination of fluoride in biological materials by means of gas chromatography. Pharm Weekbl 1968;103:909-914.

15. Yap AU, Tham SY, Zhu LY, Lee HK. Short-term fluoride release from various aesthetic restorative materials. Oper Dent 2002;27:259-265

16. Kahama RW, Damen JJ, ten Cate JM. Enzymatic release of sequestered cows' milk fluoride for analysis by the hexamethyldisiloxane microdiffusion method. Analyst 1997;122: 855-858.

17. Koparal E, Ertuḡrul F, Öztekin K. Fluoride levels in breast milk and infant foods. J Clin Pediatr Dent 2000;24: 299-302. 
18. World Health Organization. Environmental Health Criteria 227. Geneva: 2002.

19. Li Y, Liang CK, Katz BP, Brizendine EJ, Stookey GK. Longterm exposure to fluoride in drinking water and sisterchromatid exchange frequency in human blood lymphocytes. J Dent Res 1995;74:1468-1474.

20. Latifah R, Razak IA. Fluoride levels in mother's milk. J Pedod 1989;13:149-154.

21. Ekstrand J, Boreus LO, de Chateau P. No evidence of transfer of fluoride from plasma to breast milk. Br Med J 1981; 283:761-762. 